\title{
Effects of Prior Corrosion with and Without Stress on the Mechanical Properties of 7475-T761 Aluminum Alloy
}

\author{
Zuo-Yan Ye $\cdot$ Dao-Xin Liu $\cdot$ Meng Yuan • \\ Xiao-Ming Zhang $\cdot$ Zhi Yang $\cdot$ Ming-Xia Lei
}

Received: 11 October 2014/Revised: 4 December 2014/Published online: 14 February 2015

(C) The Chinese Society for Metals and Springer-Verlag Berlin Heidelberg 2015

\begin{abstract}
The effect of prior corrosion on the mechanical properties of 7475-T761 aluminum alloy was investigated by immersion test, stress corrosion test, cathode charge method and electrochemical polarization test. Results show that prior corrosion in the solution with $3 \mathrm{wt} \% \mathrm{NaCl}$ and $0.5 \mathrm{wt} \% \mathrm{H}_{2} \mathrm{O}_{2}$ leads to mechanical properties deterioration of 7475-T761 aluminum alloy. Moreover, the elongation decreases significantly. This is mainly attributed to electrochemical corrosion and hydrogen embrittlement, in which corrosion plays a major role. Tensile stress promotes the degradation of the mechanical properties by accelerating the pitting corrosion and hydrogen embrittlement.
\end{abstract}

\section{KEY WORDS: Prior corrosion; Corrosion with stress; 7475 aluminum alloy; Mechanical properties; Hydrogen embrittlement}

\section{Introduction}

Corrosion is one of the important factors that result in safety problems to aircraft aluminum structures, particularly when combined with stress. It will greatly accelerate the degradation of the mechanical properties of aircraft structures. High-strength aluminum alloy mainly suffers localized corrosion such as pitting corrosion, intergranular corrosion and exfoliation corrosion in the corrosive environment $[1,2]$. The localized corrosion decreases the load-carrying capacity of the aluminum structure, and fatigue crack would appear easily at the corrosion defect, thus reducing the fatigue strength of the aluminum [3-6]. When exposed to

Available online at http://link.springer.com/journal/40195

Z.-Y. Ye · D.-X. Liu $(\bowtie) \cdot$ M. Yuan

Corrosion and Protection Research Laboratory, Northwestern

Polytechnical University, Xi' an 710072, China

e-mail: Liudaox@nwpu.edu.cn

X.-M. Zhang $\cdot$ Z. Yang $\cdot$ M.-X. Lei

Aviation Industry Corporation of China the First Aircraft Institute, Xi' an 710089, China corrosion and tensile stress, stress corrosion cracking would occur in high-strength aluminum alloy [7-9]. Hydrogen atoms generated in the corrosion process will penetrate into the aluminum interior by the drive effect of tensile stress, gather at microscopic defects such as grain boundaries and the interface of the precipitated particles and the matrix, then lead to the decreasing of the interface bonding, and thus cause brittle fracture to the high-strength aluminum alloy.

Aircrafts generally park on the ground in the most of their calendar life. Statistically, military aircrafts and civilian aircrafts park at the airport for more than $95 \%$ and $65 \%$ of their calendar life, respectively. Aircraft structures suffer the corrosion effect of the airport atmospheric environment during the parking time. In particular, when an aircraft is parked in coastal areas or hot wet areas, the corrosion effect of the atmosphere will be more significant. Some of the aircraft structures suffer sole corrosive environment, but others are affected by the coupling action of corrosion and gravity-induced tensile stress. During the flight, aircraft structures experience static force or cyclic load, while the corrosion effect of the high-altitude environment is extremely slight and can be neglected. Therefore, aircraft structures can be considered as working with 
prior corrosion damage [10]. Some researches have focused on the corrosion-induced mechanical properties deterioration of the high-strength aluminum alloy. Most researchers [11-13] believe that the main contribution of the prior corrosion to the mechanical properties degradation is producing corrosion defects. Fatigue crack can easily appear at the defects, and thus the prior corroded aluminum alloy has a lower fatigue life. However, other researchers [14-16] indicate that even if immersed in the corrosive media without stress, the effect of hydrogen could not be neglected. The elongation to failure of the aluminum alloy significantly decreases by the coupling action of the corrosion and hydrogen embrittlement. Therefore, the mechanism of the aluminum mechanical properties deterioration caused by prior corrosion needs further studies.

In this work, the effect of prior corrosion with and without tensile stress on the mechanical properties deterioration of 7475-T761 aluminum alloy was studied. Cathode charge method was employed to investigate whether hydrogen plays a role in the degradation process. The purpose of this work is to provide a reference for the secure application of highstrength aluminum alloy to aircrafts.

\section{Material and Experiments}

\subsection{Material and Samples}

Specimens for corrosion exposure and tensile test were machined from 2.4-mm-thick, extruded 7475-T761 aluminum alloy plates, with the composition of $\mathrm{Al}-5.70 \mathrm{Zn}-$ $2.25 \mathrm{Mg}-1.55 \mathrm{Cu}-0.12 \mathrm{Fe}-0.10 \mathrm{Si}-0.06 \mathrm{Mn}$ (in wt $\%$ ). These plates were solution-treated at $495{ }^{\circ} \mathrm{C}$ for $30 \mathrm{~min}$, quenched in water to room temperature, and then aged at $120{ }^{\circ} \mathrm{C}$ for $3 \mathrm{~h}$. The tensile properties along the $\mathrm{T}$ orientation are: yield strength $457 \mathrm{MPa}$, tensile strength $515 \mathrm{MPa}$, and elongation $16.5 \%$. The optical image of the 7475-T761 aluminum alloy is shown in Fig. 1.

\subsection{Prior Corrosion Test}

Prior corrosion with and without tensile stress tests was carried out by the device shown in Fig. 2. Dog bone-shaped specimens were cut in the $\mathrm{L}-\mathrm{T}$ (long-transverse) direction (see Fig. 1) with a working length of $25 \mathrm{~mm}$, width of $5 \mathrm{~mm}$ and thickness of $2.3 \mathrm{~mm}$. Samples were polished by number 1200 emery paper and then cleaned in anhydrous alcohol and distilled water. The sample was fixed in the plexiglass container, and the non-working section was sealed with silicone rubber. The corrosive medium was the solution with $3 \mathrm{wt} \% \mathrm{NaCl}$ and $0.5 \mathrm{wt} \% \mathrm{H}_{2} \mathrm{O}_{2}$. Decomposition of the $\mathrm{H}_{2} \mathrm{O}_{2}$ enables the environment to maintain

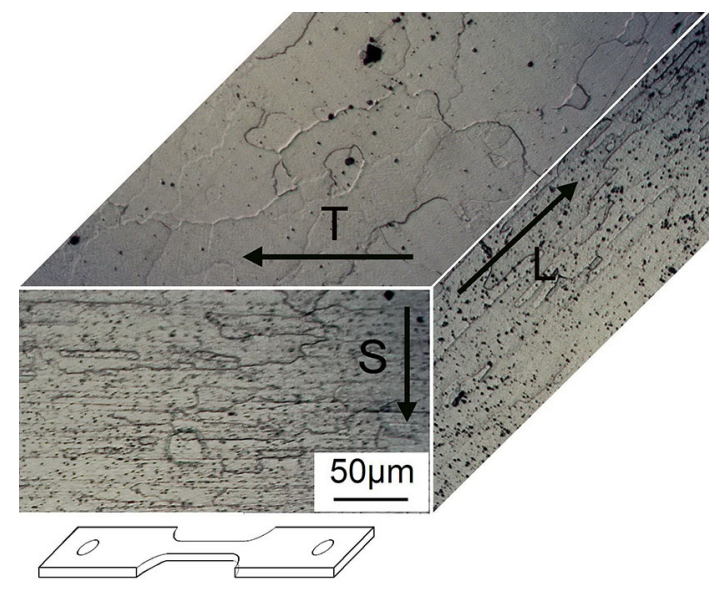

Fig. 1 Optical image of 7475-T761 aluminum alloy

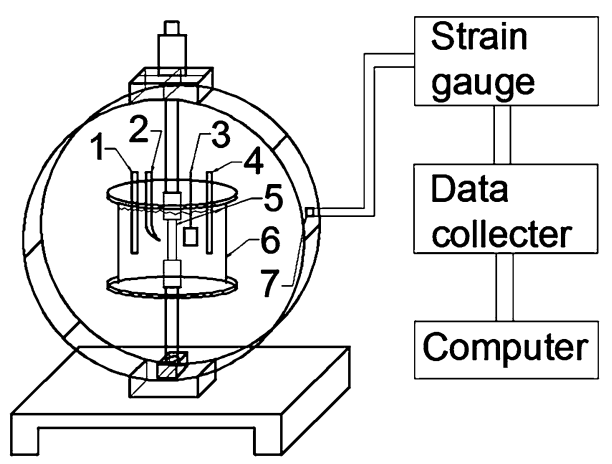

Fig. 2 Schematic diagram of stress ring device ( 1 themocouple, 2 Luggin capillary, 3 platinum plate, 4 heating element, 5 sample, 6 plexiglass container, 7 strainfoil)

adequate dissolved oxygen to simulate the corrosion environment of aircraft structures with thin water film. Tensile stress with a magnitude of $75 \%$ of the yield strength was loaded by the stress ring device shown in Fig. 2. The stress was measured by the strain gauge and computer. If the samples were cracked, the cracking time also can be recorded by the computer. The solution temperature was controlled at $35 \pm 1{ }^{\circ} \mathrm{C}$ by the temperature controller, and the solution was replaced every $24 \mathrm{~h}$. The test duration time was selected as 7, 15 and 30 days to study the variation rule of mechanical properties with time. At least 3 samples were used in each test condition. After the test, six relatively serious pits were picked out on every sample, and the depth of which was measured by a dial gage with a thin needle. Tensile test was carried out on the unbroken samples to get their mechanical properties.

\subsection{Cathodic Polarization Test}

The effect of hydrogen on the mechanical properties of 7475-T761 aluminum alloy was studied by cathodic polarization test. Samples were polarized to $-1.5 \mathrm{~V}$ (vs. 
saturated calomel electrode) in $3 \mathrm{wt} \% \mathrm{NaCl}+0.5 \mathrm{wt} \%$ $\mathrm{H}_{2} \mathrm{O}_{2}$ solution with and without tensile stress. Tensile stress with a magnitude of $75 \%$ of the yield strength was loaded by the stress ring device shown in Fig. 2. The potential was controlled by a HDV-7C potentiostat. The cathodic polarization tests were lasted for 7 days, and then the samples were subjected to tensile test.

\subsection{Electrochemical Test}

Potential dynamic tests were conducted to study the effect of tensile stress on the corrosion behavior of 7475-T761 aluminum alloy using a PARSTAT-2273 electrochemical workstation. A standard three-electrode system with the sample as the working electrode, a saturated calomel electrode (SCE) as the reference electrode and a platinum sheet as the counter electrode, was used in the tests. Tests were taken in $3 \mathrm{wt} \% \mathrm{NaCl}+0.5 \mathrm{wt} \% \mathrm{H}_{2} \mathrm{O}_{2}$ solution with a temperature of $(35 \pm 1){ }^{\circ} \mathrm{C}$, and the exposed area was $1 \mathrm{~cm}^{2}$.

\section{Results}

\subsection{Depth of Corrosion Pits Varying with Time}

Figure 3 shows the corrosion pit depth of the prior corroded samples varying with time. The pit depth increases with immersion time. The largest and average pit depth of the loaded samples is always greater than that of the unloaded samples. This demonstrates that the corrosion pit growth is accelerated by tensile stress. The pit depth of the unloaded samples increases linearly over corrosion time. However, the pit depth of the loaded samples is growing

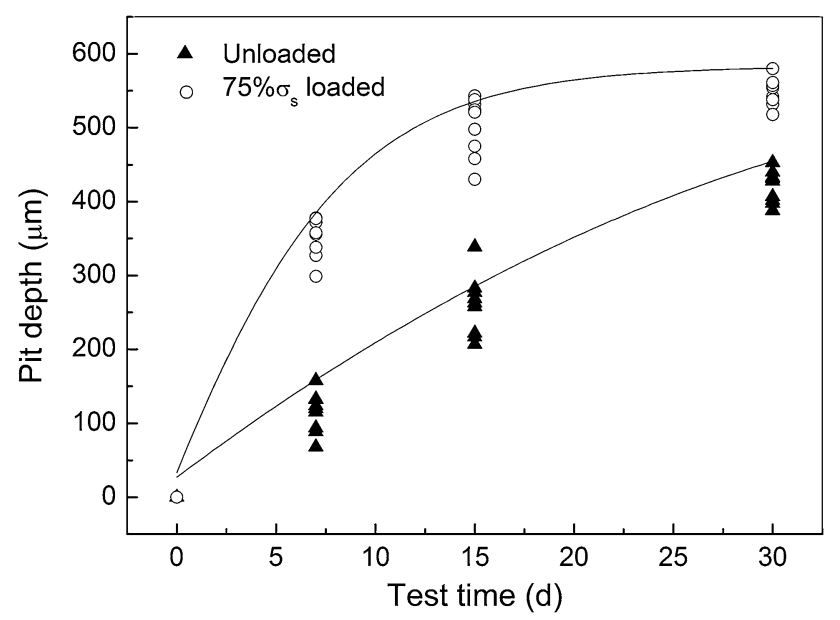

Fig. 3 Corrosion pit depth varying with time fast during the beginning 15 days, and then the growing speed slows down rapidly.

\subsection{Effects of Prior Corrosion on Mechanical Properties}

All the samples did not crack during the corrosion test. This indicates that 7475-T761 aluminum alloy has a good stress corrosion cracking resistance. In order to study the effect of corrosion on the mechanical properties of 7475-T761 aluminum alloy, the prior corroded samples were tensile tested. Figures 4 and 5 show the residual strength and elongation, respectively. As shown in Fig. 4, in the beginning 15 days, corrosion with and without tensile stress has no significant effect on the strength of the aluminum alloy. However, when the corrosion time extends to 30 days, the strength is significantly reduced, while the variance of the test results is increased. There is no obvious difference between the residual strength of the loaded and unloaded samples, and this indicates that tensile stress has no remarkable influence on the strength degradation.

As shown in Fig. 5, the elongation of the prior corroded samples decreases evidently over time, and that of the loaded samples is reduced more seriously. It appears that corrosion can significantly decrease the ductility of the 7475-T761 aluminum alloy, and tensile stress can accelerate the ductility losses.

\subsection{Effects of Cathodic Polarization on Mechanical Properties}

After 7 days of cathodic polarization, no discernible corrosion pit was observed on the loaded and unloaded samples. Then the samples were tensile tested. The strength of

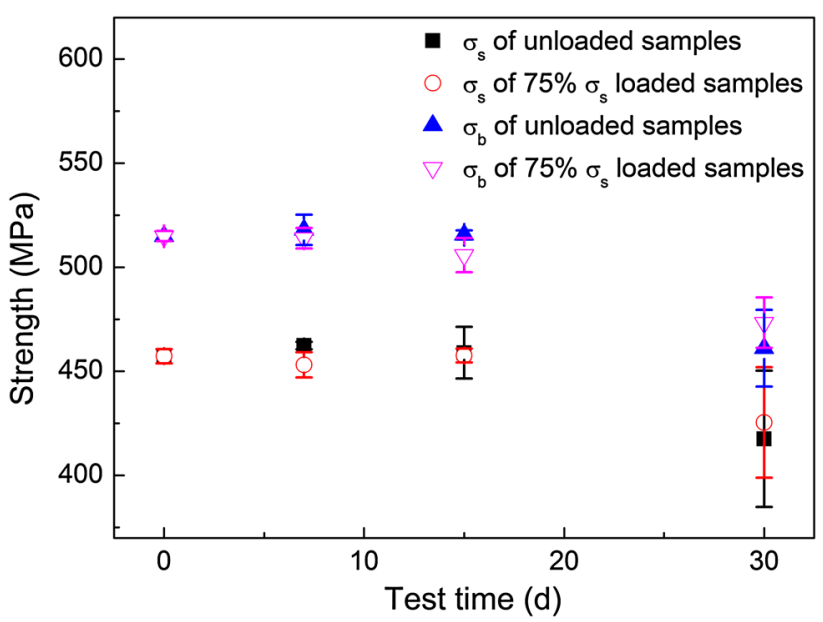

Fig. 4 Residual strength of samples varying with test time 


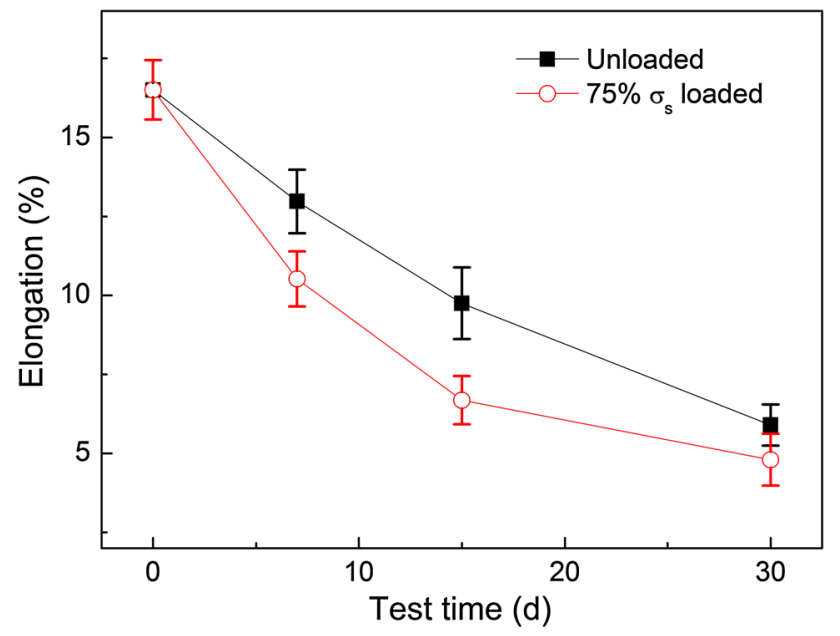

Fig. 5 Residual elongation of samples varying with test time

the cathodic polarized samples is about the same as that of the base material, but the ductility is decreased. Figure 6 compares the elongation of the prior corroded samples and the cathodic polarized samples with the same test time. The elongation of the cathodic polarized samples without tensile stress is distinctly reduced, and that of the loaded samples is reduced more pronouncedly. This indicates that tensile stress accelerates the hydrogen permeation process. Compared with that of the prior corroded samples, the elongation deterioration of the cathodic polarized samples is less serious. This verifies that hydrogen permeation plays a non-negligible role on the ductility degradation of the 7475-T761 aluminum alloy, but corrosion-induced pits play a more important role.

\subsection{Fractography}

Figure 7 shows the fracture surface of a sample prior corroded 7 days without stress. The fracture morphology of the

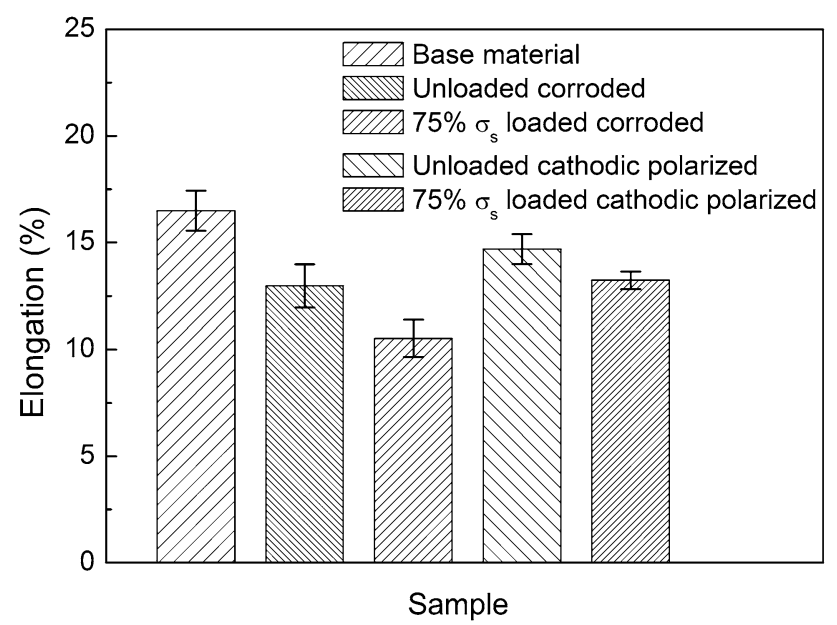

Fig. 6 Elongation of the samples after 7 days of test tension specimens can be divided into three regions: the corrosion zone, the quasicleavage zone and the ductile fracture zone. The corrosion zone almost loses mechanical properties completely. The quasicleavage zone is adjacent to the bottom of the pit. The ductile fracture is observed in the inner region. These characteristics can also be found in the fracture surface of other prior corroded samples. The quasicleavage fracture is induced by hydrogen embrittlement $[14,17,18]$. This indicates that the degradation of mechanical properties is attributed to the combination action of electrochemical corrosion and hydrogen embrittlement.

Figure 8 shows the tensile fracture surface of the cathodic polarized samples without stress. No corrosion pits are found on the edge of the fracture surface. The quasicleavage fracture is observed along the edge of the fracture surface. This is induced by the hydrogen embrittlement accelerated by cathodic polarization. The fracture characteristics of the samples with tensile stress are the same as those of the samples without stress, but the depth of the quasicleavage region is greater.

\subsection{Effect of Tensile Stress on the Electrochemical Behavior}

Figure 9 shows the potentiodynamic polarization curves of the 7475-T761 aluminum alloy with and without stress. Corrosion potential $\left(E_{\text {corr }}\right)$ and corrosion current density $\left(i_{\text {corr }}\right)$ values are presented in Table 1 . Compared with that of the unloaded samples, the $E_{\text {corr }}$ of the loaded sample is slightly decreased and the $i_{\text {corr }}$ is increased by about ten times. It is verified that tensile stress could promote the corrosion tendency of the aluminum alloy and accelerate the electrochemical corrosion process.

\section{Discussion}

Prior corrosion with and without stress both lead to mechanical properties deterioration of 7475-T761 aluminum alloy. The deterioration increases with the extension of corrosion time, especially the elongation. The strength is less sensitive to the corrosion compared to the elongation, and it decreases evidently only when the corrosion damage accumulates to a certain extent.

The variety of the pit depth with time is well related to the mechanical properties deterioration of 7475-T761 aluminum alloy. This indicates that corrosion plays an important role in the deterioration of mechanical properties. Pits cause stress concentration to the sample surface; when the sample was tensile tested, cracks appear easily at the corrosion pit $[11,19,20]$. The pit depth increases with the extension of corrosion time, so the stress concentration factor continually enlarges, and the mechanical properties 

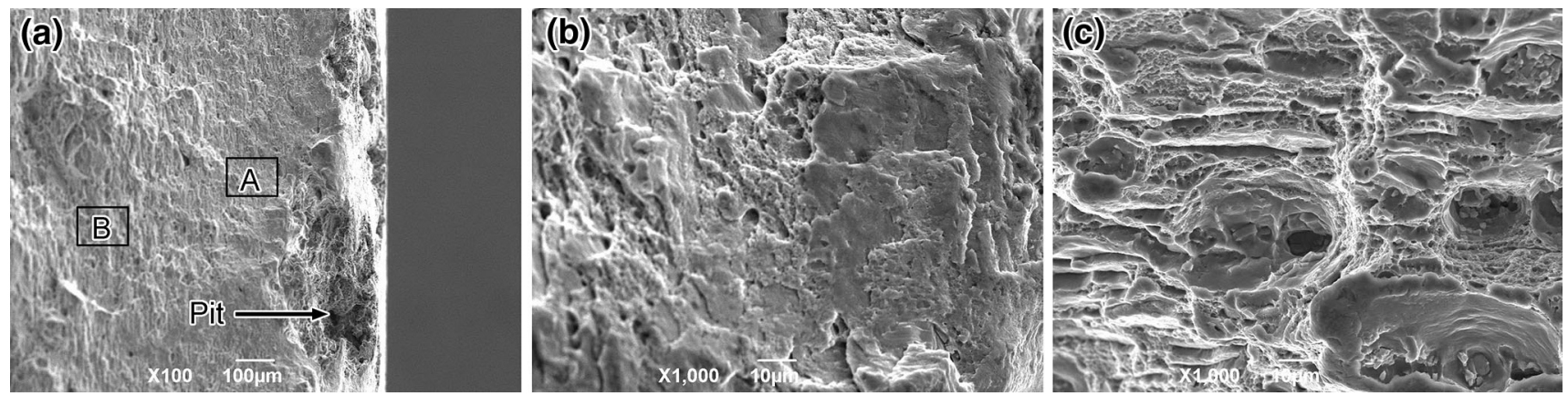

Fig. 7 a Fracture surface of a prior corroded 7-day sample without stress, $\mathbf{b}$ magnified image of the quasicleavage region, denoted by $A$ in a, c magnified image of the ductile region, denoted by $B$ in $\mathbf{a}$
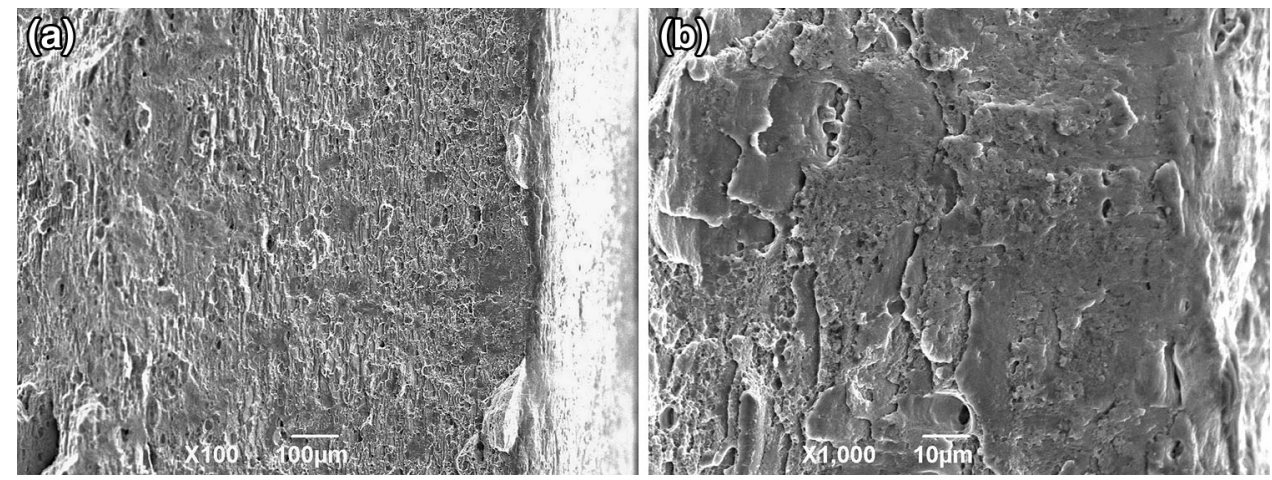

Fig. 8 Fracture surface of a cathodic polarized sample (-1.5 V vs. SCE, 7 days) without stress: a inner and edge, b quasicleavage region at the edge of fracture surface

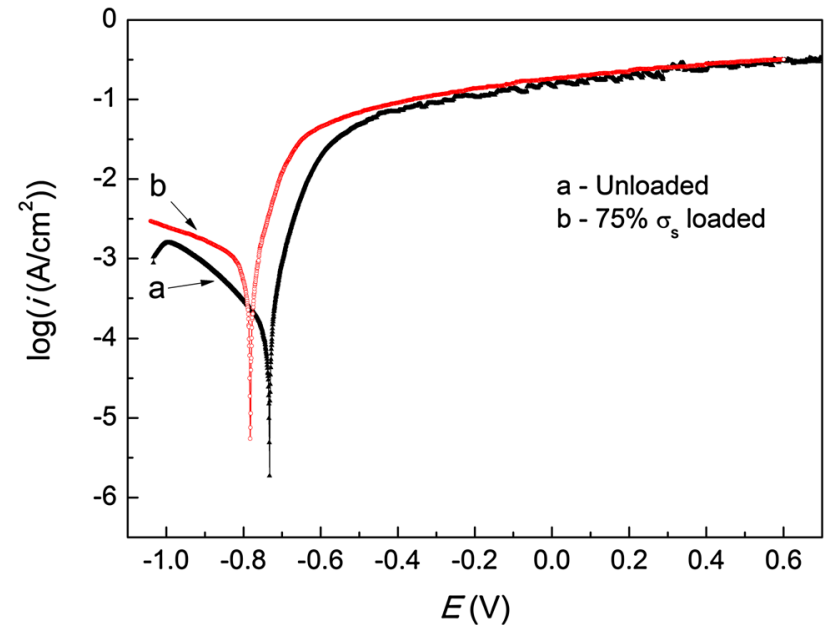

Fig. 9 Potentiodynamic polarization curves of 7475-T761 aluminum alloy in $3.5 \mathrm{wt} \% \mathrm{NaCl}+0.5 \mathrm{wt} \% \mathrm{H}_{2} \mathrm{O}_{2}$ solution with and without stress

Table 1 Fitting data of polarization curves

\begin{tabular}{lll}
\hline Sample & $E_{\text {corr }}(V)$ & $i_{\text {corr }}\left(\mathrm{mA} / \mathrm{cm}^{2}\right)$ \\
\hline Unloaded & -0.730 & 0.1445 \\
$75 \% \sigma_{\mathrm{s}}$ loaded & -0.777 & 1.062 \\
\hline
\end{tabular}

degradation becomes more and more serious. The elongation is more sensitive to the notch effect than the strength and, consequently, decreases remarkably with corrosion time. The strength does not decrease until the pit depth reaches a certain value. Tensile stress can promote the electrochemical activity of aluminum [21], and thus the electrochemical corrosion rate increases. The initiation and growth of the corrosion pit is promoted. Therefore, mechanical properties of the prior corroded samples with $75 \%$ $\sigma_{\mathrm{s}}$ tensile stress decrease more evidently. Namely, tensile stress coupling with corrosion accelerates the mechanical properties deterioration of 7475-T761 aluminum alloy.

The elongation degradation induced by cathodic polarization indicates that 7475-T761 aluminum is sensitive to the hydrogen embrittlement. According to Refs. [17, 18], the appearance of quasicleavage zone in the fracture surface (as shown in Fig. 7) is the evidence of hydrogen embrittlement. This indicates that hydrogen embrittlement plays a non-negligible role in the mechanical properties degradation of the prior corroded samples. In the test solution, hydrogen is originated from the actions: $\mathrm{Al} \rightarrow \mathrm{Al}^{3+}+3 \mathrm{e}^{-}, \mathrm{H}_{2} \mathrm{O}+$ $\mathrm{e}^{-} \rightarrow \mathrm{OH}^{-}+\mathrm{H}[22]$. When the active hydrogen atoms are generated, they adsorb to the aluminum alloy matrix or the corrosion product surface. One section of the adsorbed hydrogen is combined to form hydrogen gas then escape, and 
the other section penetrates into the aluminum alloy. The hydrogen would gather in the grain boundaries or the interfaces between the matrix and the precipitates and induce hydrogen embrittlement. Tensile stress can promote both the hydrogen-producing and hydrogen-penetrating processes [7, 8]. Particularly, when the corrosion pit is appeared on the sample surface, the externally applied tensile stress induces high triaxial stress at the bottom of the corrosion pit. The hydrogen generated at the bottom of the corrosion pit can easily penetrate into the aluminum accelerated by the tensile stress. Therefore, tensile stress promotes the hydrogen embrittlement process and aggravates the elongation degradation of cathodic polarized samples. Most reports [11-13] about the corrosion-induced mechanical properties degradation consider producing corrosion defects as the main contribution of prior corrosion. However, by comprehensively analyzing the test results, the authors attribute the mechanical properties degradation of 7475-T761 aluminum alloy to the electrochemical corrosion and corrosioninduced hydrogen embrittlement.

The prior corroded samples suffer both corrosion and hydrogen embrittlement, while the cathodic polarized samples suffer inhibited corrosion and promoted hydrogen embrittlement. The elongation shown in Fig. 6 indicates that the ductility deterioration of the prior corroded samples is more serious than that of the cathodic polarized samples. This means that corrosion plays a major role in ductility deterioration. In the neutral $3 \mathrm{wt} \% \mathrm{NaCl}+0.5 \mathrm{wt} \% \mathrm{H}_{2} \mathrm{O}_{2}$ solution, the main cathodic reaction is the reduction of the oxygen, and the hydrogen evolution action only makes up a very little proportion [23]. However, when the corrosion pit is formed, the oxygen content of the solution inside the corrosion pit is decreased by oxygen consuming without replenishing, and the solution $\mathrm{pH}$ value is decreased by the self-catalyzing acidizing action in the closed environment. The hydrogen evolution action inside the corrosion pit would be promoted by the high $\mathrm{H}^{+}$and low oxygen concentration. The appearance of the corrosion pit accelerates the hydrogen embrittlement process, and this is in accordance with Kannan's report [18]. The hydrogen evolution is promoted by the cathodic polarization, but it only makes up a very little proportion of the cathodic reaction. Therefore, the elongation degradation of prior corroded samples is more serious than that of the cathodic polarized samples.

\section{Conclusions}

1. Prior corrosion in $3 \mathrm{wt} \% \mathrm{NaCl}+0.5 \mathrm{wt} \% \mathrm{H}_{2} \mathrm{O}_{2}$ solution with and without stress both cause mechanical properties deterioration of 7475-T761 aluminum alloy. The elongation is reduced quickly with test time, while the strength is decreased evidently only when the corrosion damage accumulates to a certain extent.

2. Corrosion and corrosion-induced hydrogen embrittlement play a major role in the mechanical properties deterioration of 7475-T761 aluminum.

3. Tensile stress promotes the mechanical properties deterioration by accelerating the corrosion and the hydrogen embrittlement process.

Acknowledgments This work was financially supported by the National Natural Science Foundation of China (No. 51171154) and the National Defense Key Disciplines Laboratory of Light Alloy Processing Science and Technology, Nanchang Hangkong University (Grant No. gf 201401001).

\section{References}

[1] Z. Ye, D. Liu, C. Li, X. Zhang, Z. Yang, M. Lei, Acta Metall. Sin. (Engl. Lett.) 27, 705 (2014)

[2] B. Wang, L. Zhang, Y. Su, Y. Xiao, J. Liu, Acta Metall. Sin. (Engl. Lett.) 26, 581 (2013)

[3] J.T. Burns, S. Kim, R.P. Gangloff, Corros. Sci. 52, 498 (2010)

[4] S. Kim, J.T. Burns, R.P. Gangloff, Eng. Fract. Mech. 76, 651 (2009)

[5] K. Jones, D.W. Hoeppner, Corros. Sci. 48, 3109 (2006)

[6] K. Jones, D.W. Hoeppner, Corros. Sci. 47, 2185 (2005)

[7] E. Pouillier, A.F. Gourgues, D. Tanguy, E.P. Busso, Int. J. Plast. 34, 139 (2012)

[8] N. Takano, Mater. Sci. Eng. A 483, 336 (2008)

[9] J. Woodtli, R. Kieselbach, Eng. Fail. Anal. 7, 427 (2000)

[10] W. Liu, Y. Li, Evaluation technique for calendar life system of aircraft structure (Aviation Industry Press, Beijing, 2004). (in Chinese)

[11] B.R. Crawford, C. Loader, Q. Liu, T.J. Harrison, P.K. Sharp, Int. J. Fatigue 61, 304 (2014)

[12] S. Lv, Y. Cui, X. Gao, T.S. Srivatsan, Mater. Sci. Eng. A 574, 243 (2013)

[13] K.V. Walde, B.M. Hillberry, Int. J. Fatigue 30, 106 (2008)

[14] P.V. Petroyiannis, A.T. Kermanidis, P. Papanikos, S.G. Pantelakis, Theor. Appl. Fract. Mec. 41, 173 (2004)

[15] S.G. Pantelakis, P.G. Daglaras, C.A. Apostolopoulos, Theor. Appl. Fract. Mec. 33, 117 (2000)

[16] A.T. Kermanidis, D.G. Stamatelos, G.N. Labeas, S.G. Pantelakis, Theor. Appl. Fract. Mec. 45, 148 (2006)

[17] H. Kamoutsi, G.N. Haidemenopoulos, V. Bontozoglou, S. Pantelakis, Corros. Sci. 48, 1209 (2006)

[18] M.B. Kannan, W. Dietzel, Mater. Des. 42, 321 (2012)

[19] R.M. Pidaparti, R.R. Patel, Mater. Lett. 62, 4497 (2008)

[20] X. Li, X. Wang, H. Ren, Y. Chen, Z. Mu, Corros. Sci. 55, 26 (2012)

[21] K. Darowicki, J. Orlikowski, A. Arutunow, W. Jurczak, Electrochim. Acta 51, 6091 (2006)

[22] V.S. Raja, B.S. Padekar, Corros. Sci. 75, 176 (2013)

[23] D. Liu, Corrosion and protection of materials (Northwestern Polytechnical University Press, Xi'an, 2006). (in Chinese) 